\title{
Pengendalian Perencanaan Produksi Premium Dan Harga Pesan Crude Oil Ekonomis Menggunakan Metode Peramalan Dan Economic Order Quantity ( Studi Kasus Di PT Pertamina RU II Dumai)
}

\author{
Henny Yulius, MT ${ }^{1}$, David Deska Putra ${ }^{2}$ \\ ${ }^{1}$ Jurusan Teknik Industri, Fakultas Teknologi Industri, \\ ${ }^{2}$ Universitas Putra Indonesia "YPTK" \\ Jl. Raya Lubuk Begalung Padang - Sumatera Barat \\ E-mail: henny_yulius27@yahoo.com, daviddeska_p@yahoo.com
}

\begin{abstract}
ABSTRAK
Seiring dengan perkembangan dan kemajuan teknologi saat ini, bahan bakar minyak merupakan salah satu kebutuhan dasar baik untuk industri maupun transportasi, tuntutan akan pelayanan bahan bakar ini menjadi sangat penting, dan pertamina sebagai pihak penyedia bahan bakar minyak, harus mampu memberikan jaminan ketersedian dan kelancaran produk bahan bakar minyak. Adapun tujuan penelitian ini adalah untuk meramalkan jumlah produksi premium untuk tahun 2014 dengan menggunakan metode peramalan dan software peramalan Pom QM, menghitung safety stock perbulan yang optimal dan menghitung harga pemesanan bahan baku crude oil jenis SLC yang ekonomis menggunakan metode EOQ (Economic Order Quantity) serta menemukan solusi yang tepat guna mengoptimalkan kelancaran aliran produk dan aliran informasi pada PT. Pertamina RU II Dumai. Dari hasil penelitian dan analisa kebutuhan atau perencanaan produksi premium untuk tahun 2014 adalah sebesar 6.278,624 Mega Barel dengan rata-rata perbulan sebesar 523,219 Mega Barrel dengan metode peramalan Linear Regresion menggunakan software Pom QM serta safety stock perbulannya sebesar 159,463 Mega Barrel, dan untuk total harga pesan bahan baku crude oil jenis SLC tahun 2013 adalah sebesar US\$ 3.207.968.176 setelah melakukan perhitungan harga pesan crude oil jenis SLC yang lebih ekonomis menggunakan metode EOQ (Economic Order Quantity) dengan total US\$ 2.999.034.672, dengan menggunakan metode EOQ (Economic Order Quantity) diperoleh penghematan total harga pesan bahan baku sebesar US\$ 208.933.504 nilai ini sebanding dengan harga pesan crude oil SLC selama satu bulan kedepan.
\end{abstract}

\section{Kata kunci : peramalan, premium, crude oil, dan economic order quantity}

\section{PENDAHULUAN}

\subsection{Latar Belakang}

Dengan perkembangan dan kemajuan

teknologi, bahan bakar minyak (BBM) merupakan kebutuhan dasar dalam bidang industri maupun dalam bidang transportasi yang semakin hari memiliki tingkat permintaan semakin naik karena mesin-mesin tersebut membutuhkan bahan bakar minyak, untuk memenuhi tercapainya kebutuhan BBM yang merata diberbagai sektor terutama jenis premium untuk dapat terpenuhi setiap tahunnya tanpa ada penurunan jumlah produksi ataupun kenaikan jumlah produksi
BBM jenis premium yang tidak sesuai dengan kapasitas produksi yang telah di rencanakan.

Peramalan merupakan tahapan awal dari keseluruhan perencanaan produksi. Adanya ketidakpastian dari permintaan konsumen dimasa yang akan datang menyebabkan aktivitas peramalan ini sangat dibutuhkan sebagai inputan bagi proses perencanaan produksi.

Perencanaan dalam pengadaan Crude Oil perlu dilakukan dengan tepat dan benar karena Crude Oil merupakan bahan utama dalam pengolahan di PT. Pertamina serta Crude Oil pun tidak boleh mengalami 
kelebihan (stock out). Dalam hal ini penentuan pemesanan yang paling ekonomis untuk pengolahan Crude Oil menjadi bahan bakar minyak perlu di lakukan untuk efisiensi yang bertujuan untuk pengolahan bahan baku yang dapat di lakukan secara efisien sehingga tidak terjadi kelebihan produksi yang mengakibatkan pemborosan terhadap bahan baku terutama Crude Oil.

Oleh karena itu penelitian dilakukan untuk melihat perbandingan antara metode pengadaan Crude Oil di PT. Pertamina dengan salah satu metode usulan Economic Order Quantity (EOQ). Model EOQ merupakan model inventory yang berusaha menentukan ukuran lot pemesanan sedemikian rupa, sehingga total biaya yang relevan dapat diminimalkan, sehingga dikatakan jumlah pemesanan itu adalah jumlah pemesanan yang ekonomis dan juga mengetahui biaya yang akan akan dikeluakan dalam open akses crude-crude baru.

\subsection{Rumusan Masalah}

Adapun yang menjadi rumusan masalah dalam penelitian ini adalah sebagai berikut:

1. Berapa total perencanaan produksi premium untuk tahun 2014 yang akan ditentukan menggunakan metode peramalan?

2. Berapa total pemesanan harga crude oil serta biaya yang ekonomis untuk tahun 2013 dengan menggunakan metode Economic Order Quantity?

\subsection{Batasan Masalah}

Untuk memudahkan dalam pemecahan masalah, maka dibutuhkan batasan-batasan masalah dalam laporan ini, agar pembahasan yang akan dibahas lebih terfokus, antara lain:

1. Metode yang digunakan untuk perencanaan produksi premium adalah metode peramalan, dan metode untuk pemesanan harga crude oil adalah metode EOQ (Economic Order Quantity).

2. Objek yang akan dianalisis adalah bahan bakar jenis premium, dan crude oil jenis SLC (Sumatera Light Crude).

3. Penelitian untuk perencanaan produksi premium menggunakan data aktual produksi premium tahun 2013, dan data pemesanan crude oil SLC menggunakan data pemesanan tahun 2013 yang akan diolah selama satu tahun.

\subsection{Tujuan Penelitian}

Kerja praktek ini dilakukan untuk meneliti dan menganalisa dalam hal perencanaan produksi premium dan pemesanan crude oil yang lebih ekonomis dengan uraian sebagai berikut :

1. Mengetahui jumlah perencanaan produksi premium yang tetap untuk masa yang akan datang atau tahun berikutnya menggunakan metode peramalan.

2. Mengetahui pemesanan harga crude oil SLC yang lebih ekonomis menggunakan metode Economic Order Quantity (EOQ) dengan memperhitungkan harga produk, biaya pesan dan biaya simpan.

\section{LANDASAN TEORI}

\subsection{Peramalan}

Peramalan merupakan suatu langkah awal dalm melakukan langkah pengambilan keputusan dan perencanaan. Dengan dasar peramalan ini, maka akan didapatkan data untuk sekarang atau pun masa depan melalui pengujian data di masa lalu. Setiap pengambilan keputusan yang menyangkut keadaan dimasa yang akan datang, maka pasti ada peramalan yang melandasi pengambilan keputusan tersebut. Sofyan Assauri, 1984 (Amin S. dam M.Kholil, 2013)

\subsection{Tujuan Peramalan}

Berdasarkan pada jangka waktu peramalan, tujuan kegiatan peramalan dapat diklsifikasikan menjadi 3 bagian jangka waktu, yaitu (Amin S. dan M. Kholil : 73, 2013) :

a. Jangka Pendek (Short Term)

Menentukan kuantitas dan waktu dari item dijadikan produksi. Biasanya bersifat harian ataupun mingguan dan ditentukan oleh low management.

b. Jangkah menengah (Medium Term) 
Menentukan kuantitas dan waktu dari kapasitas produksi. Biasanya bersifat bulanan ataupun kuartal dan ditentukan oleh middle management.

c. Jangka Panjang (Long Term)

Merencanakan kuantitas dan waktu dari fasilitas produksi. Biasanya bersifat tahunan, 5 tahun, 10 tahun, ataupun 20 tahun dan ditentukan oleh top management.

\subsection{Teknik Peramalan}

Banyaknya teknik dan metode yang digunakan untuk peramalan, namun dari berbagai macam pilihan teknik dan metode, kita harus bisa melihat faktor-faktor yang mempengaruhi dalam pemilihan teknik peramalan tersebut. Hal ini dilakukan untuk memperkecil resiko yang nantinya akan tibul. Factor-faktor yang harus dipertimbangkan dalam pemilihan teknik/metode peramalan (Amin S. dan M. Kholil hal 74, 2013):

1. Horizon peramalan.

2. Tingkat ketelitian.

3. Ketersediaan data.

4. Bentuk pola data.

5. Biaya.

6. Jenis dari model.

7. Mudah tidaknya penggunaan dan aplikasinya.

\subsection{Klarifikasi Teknik Peramalan}

Pada umumnya peramalan dapat dibedakan dari beberapa segi tergantung dari cara melihatnya. Apabila dilihat dari sifat penyusunannya, maka peramalan dapat dibedakan atas dua macam, yaitu : (Amin S. dam M.Kholil : 76, 2013)

1. Dilihat dari sifat penyusunanya.

a. Peramalan yang subjektif, yaitu peramalan yang didasarkan atas perasaan atau intuisi dari orang yang menyusunnya.

b. Peramalan yang objektif, yaitu peramalan yang didasarkan atas data yang relevan pada masa lalu, dengan menggunakan teknikteknik dan metode dalam penganalisaannya.
2. Dilihat dari jangka waktu ramalan yang di susun.

a. Peramalan jangka pendek, yaitu peramalan yang dilakukan untuk penyusunan hasil ramalan yang jangka waktunya satu tahun atau kurang.

b. Peramalan jangka menengah, yaitu peramalan yang dilakukan untuk penyusunan hasil ramalan yang jangka waktunya satu hingga lima tahun ke depan.

c. Peramalan jangka panjang, yaitu peramalan yang dilakukan untuk penyusunan hasil ramalan yang jangka waktunya lebih dari lima tahun yang akan datang.

3. Berdasarkan sifat ramalan yang disusun, maka peramalan dapat dibedakan atas dua macam, yaitu:

a. Peramalan Kualitatif.

Yaitu peramalan yang didasarkan atas kwalitatif pada masa lalu. Hasil peramalan yang dibuat sangat tergantung pada orang yang menyusunnya. Hal ini penting karena hasil peramalan tersebut ditentukan berdasarkan pemikiran yang bersifat intuisi, judgement atau pendapat, dan pengetahuan serta pengalaman dari penyusunannya.

b. Peramalan Kuantitatif.

Yaitu peramalan yang didasarkan atas data kuantitatif pada masa lalu. Hasil peramalan yang dibuat sangat tergantung pada metode yang dipergunakan dalam peramalan tersebut.

\subsection{Metode Peramalan dengan Regresi Sederhana}

Metode kecenderungan dengan regresi merupakan dasar garis kecenderungan untuk suatu persamaan, sehingga dengan dasar persamaan tersebut dapat diproyeksikan halhal yang akan diteliti pada masa yang akan datang. Untuk peramalan jangka pendek dan jangka panjang, ketepatan peramalan dengan metode ini sangat baik. Data yang dibutuhkan 
untuk metode ini adalah tahunan, minimal lima tahun. Namun, semakin banyak data yang dimiliki semakin baik basil yang diperoleh Bentuk fungsi dari metode ini dapat berupa : (Makridakis, Metode Dan Aplikasi Peramalan:175 :1999)

a. Konstan.

$$
\alpha=\frac{\sum_{t=1}^{n} d t}{N}=d^{\prime} t
$$

Dengan fungsi peramalan $(Y t)$

$Y t=\mathrm{a}$, dimana $\mathrm{a}=\Sigma \mathrm{Yt} / \mathrm{N}$

$\mathrm{Yt}=$ nilai tambah

$\mathrm{N}=$ jumlah periode

b. Regresi Linier.

Dengan fungsi peramalan:

$\mathrm{Yt}=\alpha+\mathrm{bt}$

Dimana :

$$
\begin{aligned}
b & =\frac{N \sum_{t=1}^{n} t \cdot d t-\sum_{t=1}^{n} d t \sum_{t=1}^{n} t}{N \sum_{t=1}^{n} t^{2}-\left(\sum_{t=1}^{n} t\right)^{2}} \\
a & =\frac{N \sum_{t=1}^{n} d t}{N}
\end{aligned}
$$

c. Kuadratis

Dengan fungsi peramalan

$\mathrm{Yt}=\alpha+\mathrm{bt}+\alpha 2$

Dimana :

$\mathrm{Dt}=a+b t+c t^{2}$

$\gamma=\left(\sum_{t=1}^{N} t^{2}\right)^{2}-N \sum_{t=1}^{N} t^{4}$

$\delta=\sum_{t=1}^{N} t \sum_{t=1}^{N} d t$

$N \sum_{t=1}^{N} t . d t$

$$
\theta=\sum_{t=1}^{N} t^{2} \sum_{t=1}^{N} d t-
$$

$N \sum_{t=1}^{N} t^{2} \cdot d t$

$\alpha=\sum_{t=1}^{N} t \sum_{t=1}^{N} t^{2}-N \sum_{t=1}^{N} t^{3}$

$\beta=\left(\sum_{t=1}^{N} t\right)^{2}-N \sum_{t=1}^{N} t^{2}$

Keterangan Simbol :

$\gamma=$ Gamma

$\boldsymbol{\theta}=$ Theta

$\boldsymbol{\beta}=$ Beta

$\boldsymbol{\delta}=$ Delta

$\boldsymbol{\alpha}=$ Alpha

d. Eksponensial

Dengan fungsi peramalan:

$\mathrm{Yt}=\mathrm{ae} \mathrm{bt}$

$$
\text { In } \mathrm{a}=\frac{\sum \operatorname{In} Y-b \sum t}{n} \quad \mathrm{~b}=
$$

$\frac{n \sum t \operatorname{In} Y-\sum t \sum \operatorname{In} Y}{n \sum t^{3}-\left(\sum t\right)^{2}}$

\subsection{Kriteria Peformasi Kesalahan Peramalan}

Besar kesalahan suatu peramalan dapat dihitung dengan beberapa cara, antara lain adalah: (Makridakis, Metode Dan Aplikasi Peramalan: 40, 1999).

1. Mean Square Error (MSE).

$$
M S E=\frac{t=1 \sum^{n}\left(d t-D^{t} t\right)^{2}}{n}
$$

Dimana :

$$
\begin{aligned}
& \mathrm{Xt}=\text { data actual periode } \mathrm{t} \\
& \mathrm{Ft}=\text { nilai ramalan periode } \mathrm{t} \\
& \mathrm{N}=\text { banyaknya periode }
\end{aligned}
$$

2. Standart Error of Estimate (SEE).

$$
S E E=\frac{\bar{\sum}_{t=1}^{\bar{n}}\left(d t-d t^{\prime}\right)^{2}}{n-f}
$$

Dimana :

$$
\begin{array}{lll}
\mathrm{F}= & \begin{array}{l}
\text { Derajat kebebasan } \\
\text { Untuk data konstan, }
\end{array} & \mathrm{f}=-1 \\
& \text { Untuk data linier, } & \mathrm{f}=-2 \\
& \text { Untuk data kuadratis, } & \mathrm{f}=- \\
& \text { Untuk data siklis, } & \mathrm{f}=-
\end{array}
$$

3. Percentage Error (PE).

$$
P E=\left(\frac{d t-D^{t} t}{d t}\right) \times 100 \%
$$

Dimana nilai dari PEt bisa positif ataupun negatif.

4. Mean Absolute Percentage Error (MAPE).

\subsection{EOQ (Economic Order Quantity)}

Setiap perusahaan selalu berusaha untuk menentukan policy penyediaan bahan dasar yang tepat, dalam arti tidak mengganggu proses produksi dan disamping itu biaya yang ditanggung tidak terlalu tinggi, maka untuk keperluan itu terdapat suatu metode EOQ (Economic Order Quantity).

EOQ sebenarnya adalah merupakan volume atau jumlah pembelian yang paling ekonomis untuk dilaksanakan pada setiap kali pembelian. Untuk memenuhi kebutuhan itu maka dapat diperhitungkan pemenuhan kebutuhan pembeliannya yang paling ekonomis yaitu sejumlah barang yang akan dapat diperoleh dalam suatu pembelian dengan menggunakan biaya yang minimal. 
Model ini dapat digunakan dengan beberapa asumsi, yaitu : (Amin S. dan M. Kholil hal 106, 2013)

1. Permintaan diketahui, tetap dan bebas.

2. Lead time antara pemesanan dan penerimaan pesanan diketahui dan konstan.

3. Penerimaan persediaan bersifat seketika dan lengkap.

4. Discount (Potongan harga) karena kuantitas tidak dimungkinkan.

5. Biaya variabel yang ada hanyalah biaya pengaturan atau pemesanan (Biaya set up) dan biaya penyimpan persedian dari waktu ke waktu.

6. Kosongnya persedian dapat di hindarkan sepenuhnya jika pemesanan jika pemesanan di lakukan pada waktu yang tepat.

Menghitung EOQ sederhana dapat digunakan dengan rumus (Amin Syukron dan M. Kholil hal 106, 2013), yaitu :

$E O Q\left(Q^{*}\right)=\frac{2 . S \cdot D}{H}$

Keterangan :

$Q^{*}=$ Jumlah barang yang optimum pada setiap pemesanan.

$\mathrm{D}=$ permintaan tahunan untuk barang persedian.

$\mathrm{S}=$ Biaya pesan untuk sekali pesan.

$\mathrm{H}=$ Biaya simpan pertahun.

\section{METODOLOGI PENELITIAN}

\subsection{Metode Pengambilan Data}

\subsubsection{Data Primer}

Adapun yang dimaksud dengan data primer adalah data yang diperoleh secara langsung dari obyek yang diteliti. Teknik yang digunakan adalah :

a. Wawancara.

Wawancara dilakukan dengan bagian Supply Chain Optimization (SCO), Refinery Planning \& Optimization (RPO), Energy Conservation \& Loss Control (ECLC), serta Process Engineering (PE). Dalam hal ini akan di ketahui data produksi aktual premium dan data pembelian crude SLC.

b. Observasi.

Observasi dilakukan dengan cara pengumpulan data yang dilaksanakan dengan jalan mengadakan peninjauan langsung pada PT. Pertamina (Persero) RU II Dumai.

\subsubsection{Data Sekunder}

Data sekunder diperoleh dari literaturliteratur atau dokumen lainya yang berhubungan dengan obyek yang diteliti.

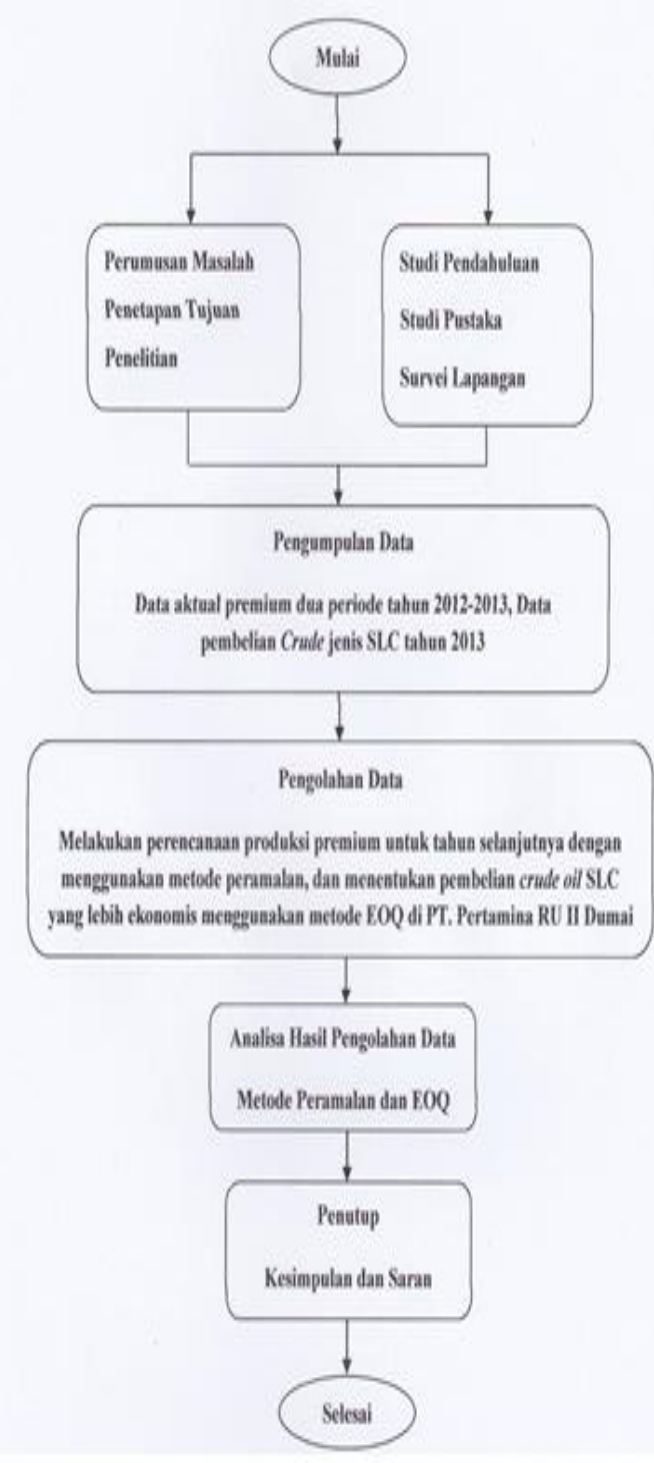

Gambar 3.1 Flow Chart Metodologi Penelitian 
Penelitian Bidang Komputer Sains dan Pendidikan Informatika

V2.i2(220-230)

\section{PENGUMPULAN DAN PENGOLAHAN DATA}

Produksi Premium dalam satuan Mega Barrel (MB) periode Januari-Desember dari 20122013 :

\begin{tabular}{|c|c|c|}
\hline \multirow{2}{*}{ Bulan } & \multicolumn{2}{|c|}{ Mega Barrel (MB) } \\
\cline { 2 - 3 } & $\mathbf{2 0 1 2}$ & $\mathbf{2 0 1 3}$ \\
\hline Januari & 616,41 & 619,622 \\
\hline Februari & 493,17 & 416,212 \\
\hline Maret & 493,17 & 412,522 \\
\hline April & 565,54 & 617,40 \\
\hline Mei & 534,957 & 513,505 \\
\hline Juni & 476,671 & 512,475 \\
\hline Juli & 535,284 & 590,583 \\
\hline Agustus & 580,879 & 541,769 \\
\hline September & 619,541 & 562,011 \\
\hline Oktober & 545,761 & 503,278 \\
\hline November & 488,18 & 471,977 \\
\hline Desember & 531,41 & 517,271 \\
\hline TOTAL & $\mathbf{6 . 4 8 0 , 5 6 3}(\mathbf{M B})$ & $\mathbf{6 . 2 7 8 , 6 2 5}(\mathbf{M B})$ \\
\hline \multicolumn{2}{|c}{}
\end{tabular}

\subsection{Metode Konstan}

Rumus Perhitungan Metode Konstan :

$\alpha=\frac{\sum_{t=1}^{n} d t}{N}=d^{\prime} t$ (Hasil)

$$
\frac{6.278,625}{12}=
$$

523,218 (d't ) Per bulan Periode Januari Desember 2014 Hasil Perhitungan metode konstan :

\begin{tabular}{|c|c|c|c|c|}
\hline$t$ & $\mathrm{dt}$ & dt'(Hasil) & $\mathrm{e}=d \mathrm{dt}-\mathrm{dt} \mathrm{t}^{\prime}$ & $\epsilon^{2}$ \\
\hline 1 & 619,622 & 523,218 & 95,404 & $9.293,731$ \\
\hline 2 & 415,212 & 523,218 & $-107,006$ & $11.450,284$ \\
\hline 3 & 412,522 & 523,218 & $-111,006$ & $12.322,332$ \\
\hline 4 & 617,40 & 523,218 & 94,182 & $8.870,249$ \\
\hline 5 & 513,505 & 523,218 & $-9,113$ & 94,342 \\
\hline 6 & 512,475 & 523,218 & $-10,743$ & 115,412 \\
\hline 7 & 590,583 & 523,218 & 67,365 & $4.538,043$ \\
\hline 8 & 541,769 & 523,218 & 18,551 & 344.139 \\
\hline 9 & 562,011 & 523,218 & 38,793 & $1.504,896$ \\
\hline 10 & 503.278 & $57,3,218$ & -19.94 & 397,603 \\
\hline 11 & 471,977 & 523,218 & $-51,241$ & $2.625,640$ \\
\hline 12 & 517,271 & 523,218 & $-5,947$ & 35,366 \\
\hline$\Sigma$ & $6.278,625$ & $6.278,616$ & & $145.839,70$ \\
\hline
\end{tabular}

Rumus Perhitungan SEE (Standard Error of Estimate) :

Keterangan: $\mathrm{f}=$ derajat kebebasan -1

$$
\begin{aligned}
\text { SEE } & =\frac{\overline{\sum_{t=1}^{n}\left(d t-d t^{\prime}\right)^{2}}}{n-f} \\
& =\frac{\frac{145.839,70}{12-1}}{\frac{145.839,70}{11}} \\
& =115,14(\mathrm{SEE})
\end{aligned}
$$

Hasil Peramalan Premium Metode Konstan:

\begin{tabular}{|c|c|}
\hline Bulan & Premium 2014 (MB) \\
\hline Januari & 523,218 \\
\hline Februari & 523,218 \\
\hline Maret & 523,218 \\
\hline April & 523,218 \\
\hline Mei & 523,218 \\
\hline Juni & 523,218 \\
\hline Juli & 523,218 \\
\hline Agustus & 523,218 \\
\hline September & 523,218 \\
\hline Oktober & 523,218 \\
\hline November & 523,218 \\
\hline Desember & 523,218 \\
\hline Total & $\mathbf{6 . 2 7 8 , 6 1 6}(\mathbf{M B})$ \\
\hline
\end{tabular}

\subsection{Metode Kuadratis}

Dalam melakukan perencanaan produksi untuk menentukan kapasitas jumlah produksi untuk 12 periode berikutnya peneliti menggunakan data aktual pada periode sebelumnya yaitu data aktual produksi premium tahun 2013, dalam hal ini peneliti mencoba melakukan peramalan perencanaan jumlah produksi premium untuk tahun 2014 menggunakan metode Kuadratis, maka apabila diselesaikan dengan Metode Kuadratis akan diperoleh hasil sebagai berikut :

Data Periode 2013 Untuk Meode Kuadratis: 
Penelitian Bidang Komputer Sains dan Pendidikan Informatika

V2.i2(220-230)

\begin{tabular}{|c|c|}
\hline $\mathbf{t}$ & $\mathbf{d t}$ \\
\hline 1 & 619,622 \\
\hline 2 & 416,212 \\
\hline 3 & 412,522 \\
\hline 4 & 617,40 \\
\hline 5 & 513,505 \\
\hline 6 & 512,475 \\
\hline 7 & 590,583 \\
\hline 8 & 541,769 \\
\hline 9 & 562,011 \\
\hline 10 & 503,278 \\
\hline 11 & 471,977 \\
\hline 12 & 517,271 \\
\hline
\end{tabular}

Hasil Perhitungan Metode Kuadratis :

\begin{tabular}{|c|c|c|c|c|c|c|c|c|c|}
\hline t & $d t$ & tit & $t$ & $t d t$ & $t^{t}$ & $t$ & $D t$ & $s=$ dit $D t$ & $s^{2}$ \\
\hline 1 & 619,622 & 619,622 & 1 & 610,622 & 1 & 1 & 432,533 & 137.099 & 35,0060 \\
\hline 2 & 116,012 & $85 ; 121$ & 1 & $1.651,818$ & 8 & 16 & $4 /, 613$ & 51.101 & 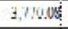 \\
\hline 3 & 112,222 & $1.237,5 ?$ & 9 & $3.712,698$ & 27 & 31 & 514,123 & 101.601 & 10,32276 \\
\hline 4 & $51: 40$ & 2.462 .60 & 15 & 9) 518,4 & 54 & 236 & $542,0=3$ & $72.24 !$ & $2,6 \% 1 \%$ \\
\hline 5 & $\$ 13,505$ & $2.567,53$ & $2 !$ & $12.837,625$ & 125 & 625 & 561,103 & 17.598 & 229128 \\
\hline 6 & 212,412 & 1.014 .82 & 35 & $18,442,1$ & 216 & $1.2 \% 6$ & $0,2,1,3$ & -99.698 & $0.06: 8:$ \\
\hline 7 & 500.583 & 4.134 .08 & 4) & 23.938 .557 & 343 & 2.431 & 574.363 & 1622 & 261.08 \\
\hline 8 & $241,66 ?$ & 4.334 .12 & 64 & $=4.6,3.216$ & 212 & $4.6 \% 6$ & $36 / 9,3$ & -26.204 & $685.6 \%$ \\
\hline 9 & 552,011 & $5.055,10$ & 31 & $45.522,991$ & 729 & 6.551 & 553,003 & 9.003 & 01.13 \\
\hline 10 & 203.218 & 2.052 .78 & 160 & 3652,8 & 1.600 & 10.000 & $20,4 \geq 3$ & $26.1 / 2$ & $68: .11$ \\
\hline 11 & 471,977 & $\$ 191,75$ & 121 & $57.109,217$ & 1.331 & 14.54 & 497,223 & .25 .146 & 642.14 \\
\hline 12 & 517.271 & $5.20 ; 25$ & 144 & 74.457 .024 & 1.529 & 20.536 & 455.613 & 50.659 & $1,679,39$ \\
\hline 78 & $5.278,63$ & 40.758 .71 & 65J & 338.321 & 6.654 & 50.710 & $6.278,62$ & & 66.571, \\
\hline
\end{tabular}

Rumus Perhitungan Metode Kuadratis yang pertama :

$$
\begin{aligned}
& \mathrm{Dt}=a+b t+c t^{2} \\
& \gamma=\underbrace{N}_{t=1}\left\{t^{2}\right\}^{2}-N_{\bar{t}=1}^{N} t^{4} \\
& \delta=\left.\underbrace{N}_{\overline{t=1}} t\right|_{\bar{t}=1} ^{N} d t \quad-N \substack{\bar{t} \overline{\bar{N}} \\
\bar{N}}_{N}^{N} t d t
\end{aligned}
$$

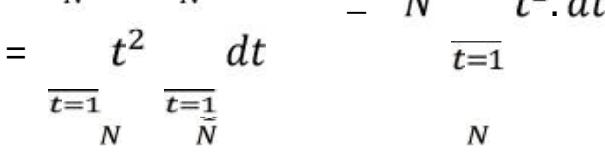

$$
\begin{aligned}
& \alpha=\overline{t=1}_{\bar{t}=1} t t^{2}-N \underset{\bar{t}=1}{ } t^{3}
\end{aligned}
$$

$$
\beta={ }_{\bar{t}=1}^{N}\left\{t^{2}\right\}^{2} \quad-N_{\bar{t}=1}^{N} t^{2}
$$

Keterangan Simbol :

$$
\begin{aligned}
& \boldsymbol{\gamma}=\text { Gamma } \\
& \boldsymbol{\theta}=\text { Theta } \\
& \boldsymbol{\beta}=\text { Beta } \\
& \boldsymbol{\delta}=\text { Delta } \\
& \boldsymbol{\alpha}=\text { Alpha }
\end{aligned}
$$

Perhitungan :

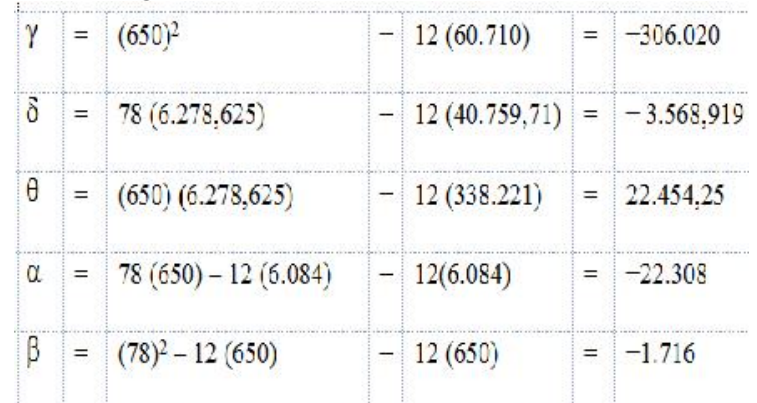

Rumus perhitungan metode Kuadratis yang ke dua :

$$
\begin{aligned}
b & =\frac{\gamma \delta-\theta \alpha}{\gamma \beta-\alpha^{2}} \\
c & =\frac{\theta-b \alpha}{\gamma} \\
a & =\frac{\sum_{t=1}^{N} d t}{N}-b \frac{\sum_{t=1}^{N} t}{N}-c \frac{\sum_{t=1}^{N} t^{2}}{N}
\end{aligned}
$$

Perhitungan:

$$
\begin{aligned}
& \begin{array}{c}
b \\
(-306.020)-3.568,919-22.454,25(-22.308)
\end{array} \\
& \hline-306.020-1.716-(22.308)^{2} \\
& =\frac{1.593 .070 .001}{27.483 .456} \\
& =57,96 \\
& c=\frac{22.454,25-57,96(-22.308)}{-306.020} \\
& =\frac{1.315 .425,93}{-306.020} \\
& =-4,29 \\
& \alpha=\frac{6.278,623}{12}-57,96 \frac{78}{12}- \\
& -4,29 \\
& =\frac{650}{12} \quad 378,853=d t^{\prime}=\text { Hasil. }
\end{aligned}
$$


Penelitian Bidang Komputer Sains dan Pendidikan Informatika

V2.i2(220-230)

Rumus perhitungan SEE (Standard Error of Estimate) :

Keterangan: $\mathrm{f}=$ derajat kebebasan, -3

$$
\begin{aligned}
\text { SEE } & =\frac{\overline{\sum_{t=1}^{n}\left(d t-d t^{\prime}\right)^{2}}}{n-f} \\
& =\frac{\frac{66.671,95}{12-3}}{\frac{66.671,95}{9}} \\
& =86,06(\mathrm{SEE})
\end{aligned}
$$

Hasil Peramalan Premium Metode Kuadratis :

\begin{tabular}{|l|c|}
\hline \multicolumn{1}{|c|}{ Bulan } & Premium (MB) 2014 \\
\hline Januari & 432,523 \\
\hline Februari & 477,613 \\
\hline Maret & 514,123 \\
\hline April & 542,053 \\
\hline Mei & 561,403 \\
\hline Juni & 572,173 \\
\hline Juli & 574,363 \\
\hline Agustus & 567,973 \\
\hline September & 553,003 \\
\hline Oktober & 529,453 \\
\hline November & 497,323 \\
\hline Desember & 456,613 \\
\hline \multicolumn{2}{|c|}{ Total } \\
\hline
\end{tabular}

\subsection{Peramalan Produksi Premium Menggunakan Software POM QM}

Dalam melakukan peramalan produksi premium tentu sangat dibutuhkan ketelitian dalam pengolahan data agar hasil peramalan yang diperoleh dapat diterapkan dengan baik. Setelah hasil pengolahan peramalan dilakukan secara manual dan didapatkan perolehan hasil peramalan dengan menggunakan metode kuadratis, maka keseragaman pengolahan data secara manual dan pengolahan data menggunakan software dapat dibandingkan. Berikut adalah perolehan hasil peramalan menggunakan software Pom Qm :

\subsubsection{Metode Linear Regression}

Hasil Peformasi Kesalahan Peramalan Premium Menggunakan Metode Linear

Regression:

\begin{tabular}{|c|c|c|c|c|c|c|c|c|c|}
\hline \multirow[t]{3}{*}{ 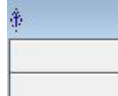 } & \multicolumn{9}{|c|}{ 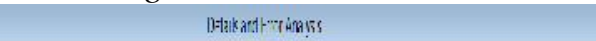 } \\
\hline & \multicolumn{9}{|c|}{ irttyinan } \\
\hline & [i:ms] d.? & $\because$ & 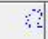 & $8 \because$ & $\because x . E$ & $E ?$ & Enry & En: & $2.1=1$ \\
\hline$x \mid 3:$ & 12 & 1 & & $\hat{x}$ & i 4 & $4, \%$ & tis & 3. & 12 \\
\hline Fno! & 13 & 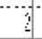 & 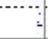 & 4 & 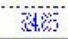 & $\because \%$ & 注 & 13t & a \\
\hline Hia: & $1 \%$ & 3 & is & Nivit & $x$ & $-1 \cdots+4$ & $\cdots$ & S徐 & $\pi$ \\
\hline sil & $\because 4$ & $\therefore$ & if. & Mit & 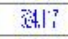 & 3 & 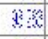 & Si: $\mathrm{P}$ & . IF: \\
\hline Hit? & FES & 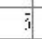 & s & Size & $5 \pi$ & $-1 ?$ & $\| 7$ & $\mid I E$ IS & $1 \%$ \\
\hline $.5 t$ & in & 3 & s & 隹证 & $2 \%$ & - & $10: 2$ & 1E: & $\hat{E}$ \\
\hline 1 & $\mathrm{ENE}$ & : & i: & $\sqrt{10}$ & 20 & 籍: & 62 & $x_{2}$ & 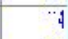 \\
\hline Acs: & atis & 3 & $\because$ & 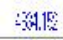 & 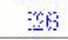 & 10\% & $1 \mathrm{x}$ & - & I \\
\hline$\hat{x p l}-\boldsymbol{x}$ & ri:" & s & 3 & $r=0$ & $2:$ & a & $x$ & T: & $\pi$ \\
\hline illat & $\mathrm{Fm}$ & 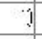 & 1 & 918 & $5 \%$ & $\therefore$ 嗍 & 3 - & $30,1,-i-$ & 籍 \\
\hline 10Ft? & $\sqrt{7 !}$ & 1 & $\therefore$ & 5\|\|$_{i=1}$ & $5 \mathrm{H}$ ? & $-4+3$ & $\because \div$ & St. & IIF \\
\hline [Ditar & 50 & $\because$ & 14: & 公政 & 73 & 4 & 3 & 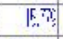 & I: \\
\hline 745 & Wh & \% & 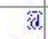 & 4 & & 1 & 忩兹 & 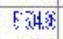 & 1 \\
\hline MEE & $5 i$ & 3 & 3 & 栤: & & 1 & $x$ & $\sqrt{x} \mathrm{~s}$ & 月 \\
\hline 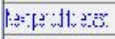 & & & & & as & $3 \mathrm{~s}$ & W & $i \leqslant=i$ & $\because \because \mathrm{FE}^{\prime}$ \\
\hline | Exat & $5 \mathrm{FE}$ & & & & & & 刢: & 7短 & \\
\hline $9 \%$ & -4 & & & & & & & & \\
\hline
\end{tabular}

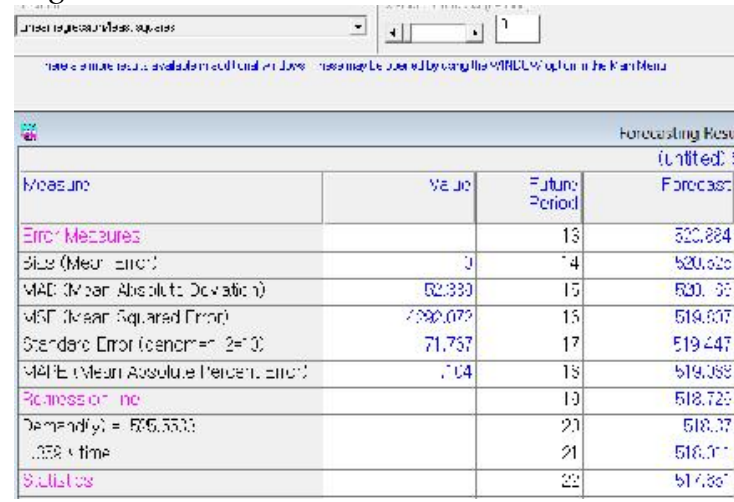

Hasil Peramalan Premium Menggunakan Metode Linear Regression:

Dari perolehan hasil peramalan dapat dilihat nilai peformasi kesalahan atau nilai erornya dan hasil peramalan perbulannya untuk kapasitas premium perbulannya, adalah sebagai berikut :

a . Nilai SEE (standard error of estimate) adalah 71,767

b . Peramalan premium untuk periode selanjutnya adalah 523,219 MB

(Mega Barrel) 
Penelitian Bidang Komputer Sains dan Pendidikan Informatika

V2.i2(220-230)

\subsection{SEE (Standard Error of Estimate) Peramalan}

Dari analisa pengolahan data yang di lakukan terhadap perhitungan peramalan perencanaan produksi yang menggunakan metode konstan, metode Regresi Linier, dan metode Kuadratis dengan memilih standard error yang terkecil di antara ke tiga metode.

\begin{tabular}{|l|c|}
\hline \multicolumn{1}{|c|}{ Metode } & $\begin{array}{c}\text { SEE (Standard Error of } \\
\text { Estimate }\end{array}$ \\
\hline Konstan & 115,14 \\
\hline Kuadratis & 86,06 \\
\hline Moving Averages & 110,32 \\
\hline $\begin{array}{l}\text { Exponential } \\
\text { Smoothing }\end{array}$ & 99,026 \\
\hline $\begin{array}{l}\text { Linear } \\
\text { Regression }\end{array}$ & $\mathbf{7 1 , 7 6 7}$ \\
\hline
\end{tabular}

Melihat hasil perbandingan tabel tersebut diatas dengan nilai SEE yang terkecil maka dapat diketahui peramalan perencanaan produksi Premium dengan Error terkecil yaitu menggunakan Metode Linear Regression dengan Standard Error yang terkecil yaitu 71,767. Maka data permintaan premium untuk 12 periode berikutnya tahun 2014 menggunakan software Pom QM dengan metode Linear Regression, dapat dilihat pada tabel berikut :

\begin{tabular}{|c|c|}
\hline \multirow{2}{*}{ Bulan } & Mega Barrel (MB) \\
\cline { 2 - 2 } & $\mathbf{2 0 1 4}$ \\
\hline Januari & 525,194 \\
\hline Februari & 524,835 \\
\hline Maret & 524,476 \\
\hline April & 524,117 \\
\hline Mei & 523,757 \\
\hline Juni & 523,398 \\
\hline Juli & 523,039 \\
\hline Agustus & 522,68 \\
\hline September & 522,321 \\
\hline Oktober & 521,962 \\
\hline November & 521,602 \\
\hline Desember & $\mathbf{5 2 1 , 2 4 3}$ \\
\hline Total & $\mathbf{6 . 2 7 8 , 6 2 4}(\mathbf{M B})$ \\
\hline Rata - Rata & $\mathbf{5 2 3 , 2 1 9}(\mathbf{M B})$ \\
\hline
\end{tabular}

4.5 Pemesanan Bahan Baku (Crude Oil) PT. Pertamina Refinery Unit II tidak melakukan kegiatan eksplorasi minyak mentah (crude oil). Kegiatan eksplorasi seluruhnya dilakukan oleh PT. Chevron pasific Indonesia (PT. CPI). Transportasi minyak mentah ini dilakukan melalui sistem perpipaan untuk Kilang Putri Tujuh (Dumai) dan melalui pengapalan Untuk Kilang Sungai Pakning. Minyak yang digunakan berupa Sumatra Light Crude (SLC) dari Duri , Duri Crude Oil dan Minas Crude. Dalam penelitian ini peneliti hanya menghitung jumlah pemesanan dan harga crude yang ekonomis dari bahan baku utama yaitu Sumatra Light Crude (SLC).

Tujuan Pemipaan Crude SLC :

\begin{tabular}{|c|cc|}
$\begin{array}{c}\text { Tarif l'esan Crude } \\
\text { Melalui Pemipan }\end{array}$ & $\begin{array}{c}\text { Tunjuan l'emipaan } \\
\text { Crude Oil SLC }\end{array}$ & ,larak \\
\hline 115 US \$ & Duri - Dumai & $88 \mathrm{Km}$ \\
\hline
\end{tabular}

Berikut adalah jumlah crude oil dan spesifikasi harga dari Januari sampai Desember 2013:

\begin{tabular}{|c|c|c|c|}
\hline Perinde 2013 & $\begin{array}{l}\text { Harga Crule } \\
\text { US\$ }\end{array}$ & $\begin{array}{l}\text { Total Crude } \\
\text { (BBL) }\end{array}$ & $\begin{array}{c}\text { Tolal Harga Crude } \\
\text { USS }\end{array}$ \\
\hline Jarluaii & 115,05 & 2.603 .213 & 301.842 .583 \\
\hline Felruati & 115,05 & 2.510 .542 & 291.097 .382 \\
\hline Maret. & 118,65 & 2.623 .492 & 311.277 .377 \\
\hline April & 110,33 & 2.169 .934 & 239.408 .873 \\
\hline Mei & 100,09 & 2.633 .761 & 263.613 .167 \\
\hline Juni & 102,75 & 2.330 .429 & 239.451 .592 \\
\hline Juli & 104,44 & 2.736 .158 & 285.761 .432 \\
\hline Agustus & 107,30 & 2.598 .462 & 278.815 .020 \\
\hline September & 113,93 & 2.439 .470 & 277.928 .856 \\
\hline Oktobcr & 108,35 & 2.613 .626 & 283.186 .382 \\
\hline Novemher & 105,96 & 2.546 .981 & 269.878 .108 \\
\hline Desember & 105,96 & 2.563 .840 & 271.664 .471 \\
\hline Total & US\$ $1.309,66$ & 29.369 .908 (BBL) & US\$ 3.207.968.176 \\
\hline
\end{tabular}

Perhitungan penentuan pemesanan dan harga yang ekonomis menggunakan metode EOQ (Economic Order Quantity), berikut rumus metode EOQ :

$Q^{*} \overline{\frac{2 S D}{H}}$

Keterangan :

$Q^{*}=$ Jumlah bahan baku yang optimum pada setiap pesanan

$\mathrm{D}=$ kebutuhan bahan baku per bulan 
Penelitian Bidang Komputer Sains dan Pendidikan Informatika

$\mathrm{S}$ = Biaya pesan untuk sekali pesan ( tarif pesan $\times$ Jarak tujuan $=$ Biaya pesan)

$\mathrm{H}=$ Biaya simpan

(Biaya simpan diasumsikan 10\%) Sumber: Pertamina RU II Dumai.

Perhitungan Pemesanan harga crude oil SLC Menggunakan Metode EOQ :

1. Januari 2013.

$\mathrm{S}=\$ 145 \times 88 \mathrm{Km}=\$ 12.760$ (biaya pesan untuk sekali pesan)

$\mathrm{D}=2.603 .213 \mathrm{Bbl}$ Kebutuhan Crude

$\mathrm{H}=\$ 115,95 \times 10 \% / 100 \%=\$$ 11,595 (Biaya simpan diasumsikan $10 \%)$

$Q^{*}=\frac{2 \times \$ 12.760 \times 2.603,213}{\$ 11.595}$

$=75.693,71327 \mathrm{Bbl}$ per hari $\times 30$ hari

$=2.270 .811,398 \mathrm{BBl}$ (Crude SLC

Januari 2013) $\times \$ 115,95$

$=$ US\$ 263.300.581 (Total harga

crude SLC Januari 2013)

2. Februari 2013.

$\mathrm{S}=\$ 145 \times 88 \mathrm{Km}=\$ 12.760$ (biaya

pesan untuk sekali pesan)

$\mathrm{D}=2.510 .542$ Bbl Kebutuhan Crude

$\mathrm{H}=\$ 115,95 \times 10 \% / 100 \%=$

$\$ 11,595$ (Biaya simpan diasumsikan $10 \%)$

$Q^{*}=\frac{\overline{2 \times \$ 12.760 \times 2.510 .542 \mathrm{Bbl}}}{\$ 11,595}$

$=74.334,20554 \mathrm{Bbl}$ per hari $\times 30$ hari

$=2.230 .026,166 \mathrm{Bbl}$ (Crude SLC

Februari 2013) $\times \$ 115,95$

$=$ US\$ 258.571.534 (Total harga

crude SLC Februai 2013)

Perolehan Hasil Perhitungan Crude SLC Menggunakan Metode EOQ:

\begin{tabular}{|c|c|c|c|}
\hline $\begin{array}{c}\text { Periode } 2013 \\
\text { Januari }\end{array}$ & $\begin{array}{l}\text { Harga Crude } \\
\text { (USS) } \\
115,95 \\
\end{array}$ & Total Crude (BBL) & $\begin{array}{c}\text { Total Harga Crude } \\
\text { (US5) } \\
263.300 .581 \\
\end{array}$ \\
\hline Fetruari & 115,95 & $2.250 .708,436$ & 258.571 .534 \\
\hline Matel & 118,65 & $2.250 .708,436$ & 267.721 .768 \\
\hline April & 110,33 & $2.125 .387,113$ & 234.193 .960 \\
\hline Mei & 100,09 & $2.245 .301,933$ & 224.732 .270 \\
\hline Juni & 102,75 & $2.282 .383,466$ & 234.514 .901 \\
\hline Juli & 101,11 & $2.153 .006,756$ & 256.192 .025 \\
\hline Agustus & 107,30 & $2.358 .413,292$ & 253.057 .746 \\
\hline September & 113,93 & $2.217 .696,0196$ & 252.655 .280 \\
\hline Oktober & 108,35 & $2.353 .796,175$ & 255.033 .815 \\
\hline November & 105,96 & $2.319 .551,581$ & 218.969 .081 \\
\hline Desember & 105,06 & $2.357 .415,173$ & 249.701 .711 \\
\hline Total & LSS $1.309,66$ & $27.515 .219,86 \mathrm{BDL}$ & US\$ 2.999.034.672 \\
\hline
\end{tabular}

Grafik Pemesanan Harga Crude Oil Jenis SLC Tahun 2013 :

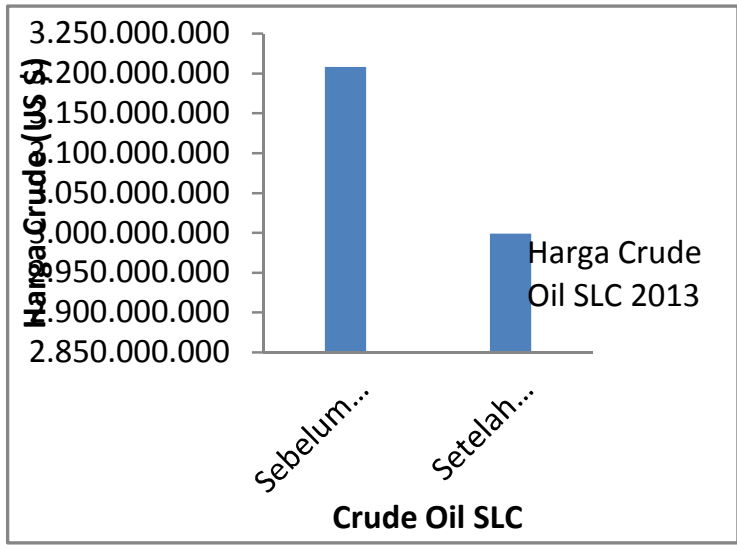

Dari perolehan hasil penghitungan pemesanan harga bahan baku crude oil jenis SLC Menggunakan Metode EOQ terlihat sangat jelas penurunan harga terhadap bahan baku, yang artinya efisiensi terhadap pembelian bahan baku lebih ekonomis.

\section{KESIMPULAN DAN SARAN \\ 6.1 Kesimpulan}

Berdasarkan uraian dan analisis yang telah dilakukan pada bab sebelumnya, maka dapat ditarik beberapa kesimpulan sebagai berikut :

1. Hasil peramalan premium untuk tahun 2014 dengan metode linear regression menggunakan Software Pom QM dengan perolehan SEE (Standard Error Of Estimate), adalah sebagai berikut :

a. Permalan premium untuk tahun 2014 adalah 6.278,624 MB dengan rata-rata perbulan 523,219 MB.

b. Perolehan SEE adalah 71,767. 
2. Perolehan distribusi frekuensi peramalan premium adalah dengan nilai 495,364536,784 MB.

3. Safety stock premium perbulan adalah 159,463 MB.

4. Hasil pemesanan crude oil SLC menggunakan metode EOQ dengan total harga pesan adalah sebesar US\$ 2.999.034.672 dan didapatkan nilai pemesanan yang lebih ekonomis sebesar US\$ 208.933.504.

\section{SARAN}

Adapun saran-saran yang dapat ditarik berdasarkan hasil penelitian ini adalah sebagai berikut :

1. Perusahaan sebaiknya meninjau kembali perencanan produksi premium yang telah dilakukan selama ini.

2. Sebaiknya pihak perusahaan dapat mempertimbangkan untuk menerapkan metode peramalan dan penggunaan software Pom QM untuk perencanaan produksi premium karena dapat merencanakan produksi dengan baik, serta metode EOQ ((Economic Order Quantity) untuk pemesanan crude oil karena dengan menggunakan metode ini kita bisa menekan biaya yang cukup besar.

3. Perusahaan sebaiknya menentukan persediaan pengaman (Safety Stock) premium karena kebutuhan dapat meningkat secara fluktuasi, sehingga dapat memenuhi kebutuhan pasar secara tepat.

\section{DAFTAR PUSTAKA}

Irianto, Agus. 2010. Statistik : Konsep Dasar Aplikasi Dan Pengembangannya. Jakarta : Prenada Media

Kusuma, Hendra. 2009. Perencanaan Dan Pengendalian Produksi. Penerbit : ANDI Yogyakarta

Makridakis, Spyros. 1999. Metode Dan Aplikasi Peramalan. Penerbit : Erlangga

Nasution, Arman Hakim. 2005. Manajemen Industri. Penerbit : Andi Yogyakarta

Nurhasanah, Siti. 2012. Analisis Persediaan Solar dengan Menggunakan Metode Economic Order Quantity (EOQ). Jurnal: Politeknik Negeri Samarinda.

Pamungkas, Wahyu Tri. 2011. Analisis Pengendali an Bahan Baku Menggunakan Metode EOQ (Economic Order Quantity). Jurnal: Universitas Ahmad Dahlan.

Syukron Amin, Muhammad Kholil. 2013. Pengantar Teknik Industri. Jakarta: Lembaga Penerbit Graha ILmu.

Yani Iriani, Beny Mulyadi. 2010. Analisis Peramalan Penjualan Bahan Bakar Minyak Jenis Premium Di SPBU Asri Bandung. Jurnal Teknik Industri : $\quad$ Universitas Widyatama. 